\title{
Degradabilidade Ruminal da Cama de Frango e do Feno de Capim Coast-Cross e Avaliação de Modelos Matemáticos para Estimativa da Taxa de Passagem de Partículas ${ }^{1}$
}

\author{
Ronaldo Lopes Oliveira², José Carlos Pereira ${ }^{3}$, Paulo Roberto de Carvalho e Silva², Ricardo \\ Augusto Mendonça Vieira ${ }^{2}$
}

\begin{abstract}
RESUMO - O experimento foi realizado para avaliar a cinética de degradação ruminal da matéria seca (MS), proteína bruta (PB) e fibra em detergente neutro (FDN) e os diferentes modelos para estimativa da taxa de passagem, em novilhos recebendo dietas com $15,0 \%$ de cama de frango, associada a dois níveis de suplemento à base de flora ruminal liofilizada de bovinos adultos ( 0 e $10 \mathrm{~g} / \mathrm{animal} \bullet \mathrm{dia})$. Quatro novilhos fistulados no rúmen e abomaso foram distribuídos em delineamento inteiramente casualizado. A taxa de passagem foi determinada por intermédio da técnica do cromo complexado à parede celular do feno de coast-cross, como indicador, e a degradabilidade, por intermédio da técnica do saco de náilon. Os modelos matemáticos foram avaliados por meio do estudo dos desvios padronizados e do número de corridas de sinal. A ingestão diária de $10 \mathrm{~g}$ do suplemento, por animal, não influiu na taxa de passagem das partículas e na degradabilidade ruminal. A cinética de passagem apresentou comportamento tempo-dependente. O modelo Dhanoa mostrou-se mais eficiente na determinação dos parâmetros relativos à taxa de passagem.
\end{abstract}

Palavras-chave: cama de frango, degradabilidade, microbiota, modelos matemáticos, taxa de passagem

\section{Coast-Cross Hay and Broiler Litter Ruminal Degradation and Evaluation of Mathematical Models to Estimate Rate of Particulate Passage}

\begin{abstract}
The experiment was conducted to evaluate the dry matter(DM), crude protein (CP) and neutral detergent fiber (NDF) degradation kinetics and different models to estimate the passage rate in steers fed diets with $15.0 \%$ of broiler litter associated to two levels of a supplement based on bovine lyophilized ruminal microbiota ( 0 and $10 \mathrm{~g} /$ animal $\bullet$ day). Four steers with ruminal and abomasal fistulae were allotted to a completely randomized experiment. The passage rate was determined using chromium complexed to the cellular wall of the coast cross hay, as a marker, and the degradability, by means of the nylon bag technique. The mathematical models were evaluated by means of standardized deviations and of the number run signals. The daily intake of $10 \mathrm{~g}$ of the supplement per animal did not affect the passage rate and ruminal degradation. The passage kinetics had a time-dependent behavior. The Dhanoa model showed to be the most efficient in the determination of the parameters related to the passage rate.
\end{abstract}

Key Words: broiler litter, degradability, microbiota, mathematical models, rate of passage

\section{Introdução}

A cinética de trânsito ou passagem refere-se ao fluxo de resíduos não-digeridos do alimento ao longo do trato digestivo e é influenciada pelo nível de consumo, pela forma física da dieta, pelas diferenças na atividade de ruminação entre animais, pelo tipo de indicador usado na determinação da curva de excreção fecal (MERTENS e ELY, 1982), pela proporção volumoso:concentrado e por fatores climáticos (FAICHNEY, 1993).

A taxa de remoção da digesta ruminal influencia a extensão da degradação protéica ( $\varnothing \mathrm{RSKOV}$ e
McDONALD, 1979), a digestão da parede celular e, conseqüentemente, a digestibilidade in vivo da dieta (VAN SOEST, 1994; ALLEN e MERTENS, 1988) e a eficiência de síntese de proteína microbiana (SNIFFEN e ROBINSON, 1987); daí a importância de se estudar a cinética de passagem das partículas. Portanto, digestão e passagem atuam de forma simultânea e competitiva para a remoção da digesta presente no rúmen, devendo-se, então, estudar os efeitos combinados de digestão e taxa de passagem, para maximizar o consumo de nutrientes digestíveis (AITCHISON et al., 1986).

Há, na literatura, várias metodologias disponíveis

\footnotetext{
${ }_{1}^{1}$ Parte da Dissertação de Mestrado do primeiro autor apresentada ao Departamento da Zootecnia da UFV.

2 Zootecnista, Estudante de Doutorado, DZO/UFV.

${ }^{3}$ Professor Titular, DZO/UFV. Bolsista do CNPq.
} 
para estimar a taxa de passagem $(\mathrm{k})$ ou o tempo médio de retenção $(1 / \mathrm{k})$ das partículas pelo trato gastrintestinal (TGI) dos ruminantes. Nos últimos anos, a estimativa da taxa de passagem tem sido realizada por meio da infusão de dose única do indicador diretamente no rúmen de animais canulados, com posterior amostragem das fezes, em intervalos de tempo conhecidos, nas quais são analisadas as concentrações do elemento químico utilizado. A curva de excreção do marcador é, então, ajustada a um modelo matemático para determinar os coeficientes relacionados à passagem das partículas.

BLAXTER et al. (1956) foram os primeiros a demonstrar que a curva de excreção fecal do marcador pode ser descrita matematicamente como a soma de dois componentes exponenciais e um tempo de atraso no processo de remoção. Ainda de acordo com esses autores, o turnover mais rápido $\left(>\mathrm{k}_{\text {ou }} \mathrm{k}_{1}\right)$ representa a saída das partículas do rúmen e o mais lento $\left(<\mathrm{k}\right.$ ou $\left.\mathrm{k}_{2}\right)$, o tempo gasto para as partículas deixarem o abomaso e aparecerem nas fezes, e a constante $\tau$, o tempo de atraso.

Esquematicamente tem-se:

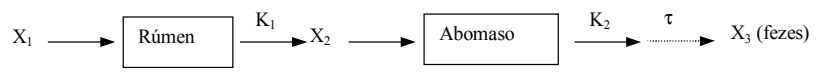

em que $X_{1}, X_{2}$ e $X_{3}$ representam as proporções de alimento presentes no rúmen, abomaso e fezes, em tempo " $t$ ", respectivamente. Quando $t=0, X_{1}=1 \mathrm{e}$ todo o marcador encontra-se no rúmen; ao contrário, quando $\mathrm{t} \rightarrow \infty, \mathrm{X}_{1} \rightarrow 0, \mathrm{X}_{2} \rightarrow 0$ e $\mathrm{X}_{3} \rightarrow 1$, todo o marcador apresentar-se-á nas fezes. Nesta representação o $\mathrm{k}_{1}$ e $\mathrm{k}_{2}$ são as taxas de passagem associadas ao rúmen e abomaso e a constante $\tau$, dada em horas, ao tempo-dependente ou de atraso.

FRANCE et al. (1985) expressaram este modelo da seguinte forma:

$$
\begin{gathered}
\frac{d \mathrm{X}_{1}}{d \mathrm{t}}=\mathrm{k}_{1} \mathrm{X}_{1}(\mathrm{t}) \\
\frac{d \mathrm{X}_{2}}{d \mathrm{t}}=\mathrm{k}_{1} \mathrm{X}_{1}(\mathrm{t})-\mathrm{k}_{2} \mathrm{X}_{2}(\mathrm{t}) \\
\frac{d \mathrm{X}_{3}}{d \mathrm{t}}=0(\text { para } 0 \leq \mathrm{t}<\tau) \text { ou } \mathrm{k}_{2} \mathrm{X}_{2}(\mathrm{t}-\tau)(\text { para } \mathrm{t} \geq \tau)
\end{gathered}
$$

A solução analítica para $\mathrm{k}_{1} \neq \mathrm{k}_{2}$, que descreve a cinética de passagem por intermédio do trato digestivo, seria $\frac{d \mathrm{X}_{3}}{d \mathrm{t}}=0$ para $0 \leq \mathrm{t}<\tau$, e

$$
\frac{d \mathrm{X}_{3}}{d \mathrm{t}}=\mathrm{k}_{1} \mathrm{k}_{2}\left(\frac{e^{\mathrm{k}_{1}(\mathrm{t}-\tau)}}{\left(\mathrm{k}_{2}-\mathrm{k}_{1}\right)}+\frac{e^{\mathrm{k}_{2}(\mathrm{t}-\tau)}}{\left(\mathrm{k}_{1}-\mathrm{k}_{2}\right)}\right), \text { para } \mathrm{t} \geq \mathrm{t} .
$$

GROVUM e WILLIAMS (1973), utilizando o modelo de BLAXTER et al. (1956), sugeriram uma explicação biológica para $k_{1}, k_{2}$ e $\tau$. Na concepção dos primeiros autores, ao contrário dos últimos, a taxa de passagem lenta $\left(\mathrm{k}_{1}\right)$ representava a saída do indicador do rúmen, ao passo que a passagem rápida $\left(\mathrm{k}_{2}\right)$ estava associada à saída pelo ceco e cólon proximal. O modelo utilizado, similar ao de BLAXTER et al. (1956), foi:

$$
\mathrm{Y}=\mathrm{Ae}^{-\mathrm{k}_{1}(\mathrm{t}-\mathrm{TT})}-\mathrm{Ae}^{-\mathrm{k}_{2}(\mathrm{t}-\mathrm{TT})} \text { para } \mathrm{t}>\mathrm{TT} \text { e } \mathrm{Y}=0
$$
para $\mathrm{t}<\mathrm{TT}$.

Neste modelo, TT é o tempo calculado para o primeiro aparecimento do marcador nas fezes e pode ser representado esquematicamente da seguinte forma:

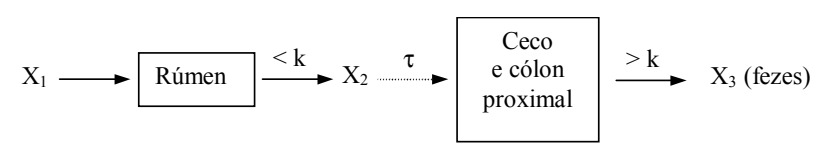

em que $X_{1}, X_{2}$ e $X_{3}$ representam as proporções de alimento presentes no rúmen, no abomaso e nas fezes, em um tempo "t", respectivamente. Quando $\mathrm{t}=0, \mathrm{X}_{1}=1$ e todo o marcador encontra-se no rúmen; ao contrário, quando $\mathrm{t} \rightarrow \infty, \mathrm{X}_{1} \rightarrow 0, \mathrm{X}_{2} \rightarrow 0$ e $\mathrm{X}_{3} \rightarrow 1$, todo o marcador apresentar-se-á nas fezes. Nesta representação, o menor e o maior k são as taxas de passagem associadas ao rúmen e ao ceco e cólon proximal, respectivamente, e a constante $\tau$, dada em horas, ao tempo-dependente ou de atraso.

MATIS (1972) observou que o tempo gasto pelas partículas para se misturarem ao meio e a redução do tamanho das mesmas alteram as probabilidades destas partículas escaparem do primeiro compartimento. Assim, esse autor sugeriu ao modelo de BLAXTER et al. (1956) o uso de uma distribuição gama, de forma a representar a dependência do tempo em que a partícula esteja presente (tempo-dependente). Esquematicamente o modelo pode ser representado da seguinte forma:

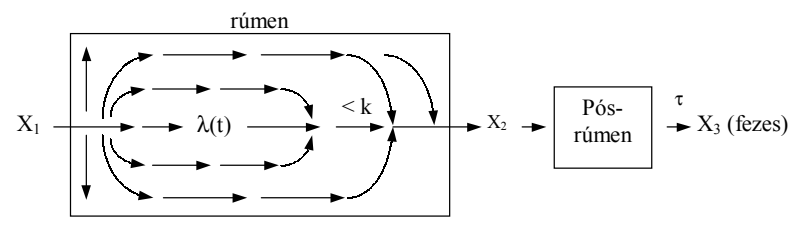

em que $X_{1}, X_{2}$ e $X_{3}$ representam as proporções de alimento presentes no rúmen, no abomaso e nas fezes, em um tempo "t", respectivamente; a constante $\tau$, dada em horas, refere-se ao tempo-dependente ou de atraso; e 1(t), à dependência do tempo da partícula no rúmen.

A sugestão de que existem mais de dois pools no 
trato digestivo foi feita por DHANOA et al. (1985), assumindo que o fluxo da digesta apresentava uma evolução de forma exponencial em "n" compartimentos. O modelo proposto também é tempo-dependente, todavia, sua abordagem matemática é diferente. Esses autores utilizam uma distribuição múltiplo-seqüencial de sub-compartimentos tempo-independentes dentro de cada compartimento, na qual cada seqüência tem uma diferença fixa na magnitude do seu turnover relativamente pequena. Assim, o fluxo através desses múltiplos compartimentos produz distribuição de taxas tempo-independentes. O modelo multicompartimental pode ser esquematizado da seguinte forma:

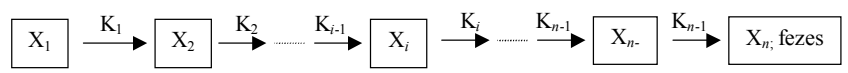

em que $X_{1}, X_{2}, \ldots, X_{n-1}$ e $X_{n}$ representam as proporções do marcador nos compartimentos em determinado tempo " $\mathrm{t}$ ", respectivamente. Quando $\mathrm{t}=0 ; \mathrm{X}_{1}, \mathrm{X}_{2}, \ldots, \mathrm{X}_{\mathrm{n}-1}=1$ e $\mathrm{X}_{\mathrm{n}}=0$; para $\mathrm{t} \rightarrow \infty, \mathrm{X}_{1}$, $\mathrm{X}_{2}, \ldots$ e $\mathrm{X}_{\mathrm{n}-1} \rightarrow 0$ e $\mathrm{X}_{\mathrm{n}} \rightarrow 1$, todo o marcador apresentar-se-á nas fezes.

A expressão matemática é $\mathrm{Y}=\mathrm{A} \mathrm{e}^{-\mathrm{k}_{1} \mathrm{t}} \exp \left[-\mathrm{Be}^{-\mathrm{k}_{2} \mathrm{t}}\right]$, em que $\mathrm{Y}$ representa a concentração de indicadores nas fezes no tempo t; A e B são parâmetros biologicamente indefinidos; $\mathrm{k}_{1} \mathrm{e}$ a taxa de passagem no rúmen; e $\mathrm{k}_{2}$, a taxa de passagem pós-ruminal.

De acordo com QUIROZ et al. (1988), o modelo a ser usado para descrever o movimento da digesta através do trato gastrintestinal ainda apresenta dúvidas e, apesar de vários modelos terem sido propostos, não existe um critério seguro para determinar qual modelo é mais apropriado para as diferentes condições encontradas.

A taxa de degradação da proteína dentro do rúmen determina não apenas a quantidade de $\mathrm{N}$ disponível aos microrganismos, mas também a quantidade que se torna disponível para a digestão no intestino (BOER et al., 1987).

Para se estabelecer a taxa de degradação dos nutrientes no rúmen, tem-se utilizado a técnica dos sacos de náilon. Este método permite o contato direto do alimento com o ambiente ruminal, não existindo melhor forma de simulação deste (temperatura, $\mathrm{pH}$, tamponamento, substrato e enzimas), e, apesar de o alimento não estar sujeito a todos os eventos digestivos, como mastigação, ruminação e passagem, permite obter valores próximos aos encontrados com ensaios in vitro (MEHREZ e ØRSKOV, 1977; NOCEK, 1988; e ROMERO, 1990).
Neste trabalho teve-se por objetivo avaliar a cinética de degradação ruminal da matéria seca (MS), proteína bruta (PB) e fibra em detergente neutro (FDN), bem como diferentes modelos para estimativa da taxa de passagem, em novilhos recebendo dietas com $15 \%$ de cama de frango associada a dois níveis de suplemento à base de microbiota ruminal liofilizada de bovinos adultos.

\section{Material e Métodos}

O experimento foi conduzido no Departamento de Zootecnia da Universidade Federal de Viçosa, em Minas Gerais, no período de setembro a dezembro de 1996.

Foram utilizados quatro novilhos, predominantemente da raça Holandesa, com idade aproximada de 1,5 anos e peso vivo médio de $307 \mathrm{~kg}$, fistulados no rúmen conforme técnicas descritas por LEÃO e COELHO DA SILVA (1980) e LEÃO et al. (1978). Estes animais foram distribuídos aleatoriamente em baias individuais cobertas, contendo comedouros individuais, bebedouros automáticos tipo concha e piso cimentado, mantidos em condições de higiene adequadas e, no período pré-experimental, foram vermifugados e vacinados contra febre aftosa.

Os animais receberam uma dieta com $15 \%$ de cama de frango, contendo ou não $10 \mathrm{~g}$ de suplemento à base de microbiota ruminal liofilizada por dia, que constituíram os tratamentos. O delineamento experimental utilizado foi o inteiramente casualizado com duas repetições por tratamento (animais) e, para o estudo de degradabilidade, havia ainda duas repetições (sacos de náilon) no rúmen de cada animal. Para os parâmetros de passagem e degradação, foram feitos testes de homogeneidade de variância e as médias foram comparadas pelo teste "t", a 5\% de probabilidade.

Os dados experimentais foram analisados utilizandose o programa SAEG - Sistema de Análises Estatísticas (UNIVERSIDADE FEDERAL DE VIÇOSA, 1995).

As composições químico-bromatológicas dos componentes constam da Tabela 1 e as proporções de cada ingrediente e a composição das dietas, da Tabela 2.

Os animais receberam feno do capim coastcross (Cynodon dactylon (L.) Pers.) como volumoso e os concentrados constituíram-se de farelo de soja e fubá de milho, além de suplemento mineral. Estes foram elaborados de modo que as dietas apresentassem teores semelhantes de PB e FDN. A dieta foi calculada para uma taxa de ganho de peso estimada de 700 a $800 \mathrm{~g} /$ dia, de acordo com o NATIONAL RESEARCH COUNCIL - NRC (1989). 
Tabela 1 - Composição química dos ingredientes (\% MS)

Table 1 - Chemical composition of the ingredients (\% DM)

\begin{tabular}{lcccc}
\hline $\begin{array}{l}\text { Componente } \\
\text { Component }\end{array}$ & $\begin{array}{c}\text { MS }(\%) \\
D M\end{array}$ & MO & PB & FDN \\
\hline $\begin{array}{l}\text { Feno de coast-cross } \\
\begin{array}{l}\text { Coast-cross hay } \\
\text { Cama de frango }\end{array}\end{array}$ & 87,64 & 92,41 & 5,95 & 83,26 \\
$\begin{array}{l}\text { Broiler litter } \\
\text { Concentrado 1 }\end{array}$ & 73,49 & 83,23 & 17,83 & 59,89 \\
$\begin{array}{l}\text { Concentrate 1 } \\
\text { Concentrado 2 }\end{array}$ & 82,17 & 96,86 & 17,33 & 25,74 \\
Concentrate 2 & 82,52 & 97,41 & 11,84 & 27,54 \\
\hline
\end{tabular}

Tabela 2 - Proporção dos ingredientes (\% MS) e teores de matéria seca (MS), matéria orgânica (MO), proteína bruta $(\mathrm{PB})$ e fibra em detergente neutro (FDN)

Table 2 - Proportion of ingredients (\% DM) and contents of dry matter (DM), organic matter (OM), crude protein (CP) and neutral detergent fiber (NDF)

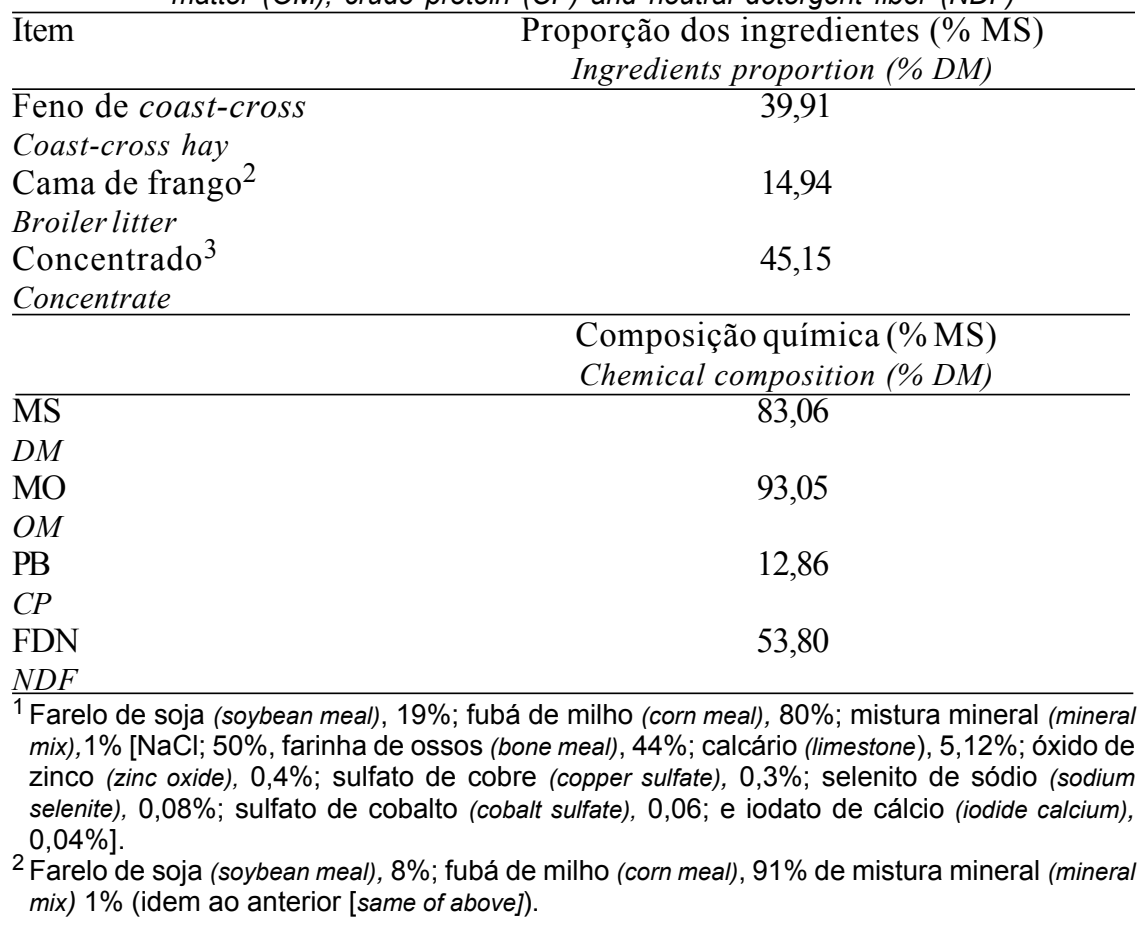

O material base da cama de frango foi o capimelefante (Pennisetum purpureum Schum.) em estádio avançado de maturação, seco e picado. Armazenou-se a cama de frango por dois meses antes do experimento, sob lona plástica, em galpão coberto. Este armazenamento foi feito com o intuito de eliminar microrganismos potencialmente patogênicos, uma vez que esse material não sofreu nenhum tipo de processamento (FONTENOT e WEBB, 1975; McCASKEY e ANTHONY, 1979).

O suplemento à base de microbiota ruminal liofilizada foi oferecido em doses de $5 \mathrm{~g}$ misturados a uma porção de concentrado duas vezes ao dia, antes de cada arraçoamento. O alimento não era servido enquanto os animais não consumissem todo o suplemento e o consumo foi determinado diariamente para ajustar as sobras em $10 \%$

A taxa de passagem das partículas foi estimada com o auxílio do Cr-FDN ou "mordente" como indicador, fixado à parede celular do feno de coast-cross, utilizando-se a técnica descrita por UDÉN et al. (1980).

Para determinar a curva de excreção do cromo, 
as amostras marcadas do feno foram colocadas diretamente no rúmen, pela fístula ruminal, uma única vez, antes da primeira alimentação. Após este procedimento, foi iniciada a coleta de fezes, durante um período de cinco dias, obtendo-se 20 amostras nos seguintes intervalos: a primeira logo após o fornecimento do indicador; as três seguintes com intervalos de 8 horas; as próximas 10 com intervalo de 4 horas; as três subseqüentes com 8 horas; e as três últimas com intervalos de 12 horas.

Para a determinação da taxa de passagem da fase sólida e do tempo de retenção de sólidos no rúmen e nos intestinos, foram avaliados três modelos compartimentais. Os modelos estudados foram os propostos por MATIS (1972), GROVUM e WILLIAMS (1973) e DHANOA et al. (1985), que, neste trabalho, foram denominados de modelo Matis, modelo GrovumWilliams e modelo Dhanoa, respectivamente. Suas descrições estão apresentadas a seguir:

- Modelo Matis

$$
\mathrm{Y}=\mathrm{Ae}^{-\mathrm{k}_{1}(\mathrm{t}-\mathrm{c})}\left[\left(\frac{\mathrm{k}_{1}^{2}(\mathrm{t}-\mathrm{TT})}{\mathrm{k}_{2}-\mathrm{k}_{1}}\right)-\left(\frac{\mathrm{k}_{1}^{2}}{\left(\mathrm{k}_{2}-\mathrm{k}_{1}\right)^{2}}\right)\right]+\mathrm{e}^{-\mathrm{k}_{2}(\mathrm{t}-\mathrm{TT})}\left(\frac{\mathrm{k}_{1}^{2}}{\mathrm{k}_{2}-\mathrm{k}_{1}}\right)^{2}
$$

para $\mathrm{t}>\mathrm{TT}$ e $\mathrm{Y}=0 \quad$ para $\mathrm{t}<\mathrm{TT}$.

\section{- Modelo Grovum-Williams}

$$
\begin{aligned}
& \mathrm{Y}=\mathrm{Ae}^{-\mathrm{k}_{1}(\mathrm{t}-\mathrm{TT})}-\mathrm{Ae}^{-\mathrm{k}_{2}(\mathrm{t}-\mathrm{TT})} \text { para } \mathrm{t}>\mathrm{TT} \mathrm{e} \\
& \mathrm{Y}=0 \text { para } \mathrm{t}<\mathrm{TT} .
\end{aligned}
$$

\section{- Modelo Dhanoa}

em que

$$
\mathrm{Y}=A \mathrm{e}^{-\mathrm{k}_{1} \mathrm{t}} \exp \left[-\mathrm{Be}^{-\mathrm{k}_{2} \mathrm{t}}\right]
$$

$\mathrm{Y}=$ concentração do indicador nas fezes;

$\mathrm{k}_{1}=$ taxa de passagem no rúmen;

$\mathrm{k}_{2}=$ taxa de passagem pós-ruminal.

$\mathrm{TT}=$ tempo em que o indicador aparece pela primeira vez nas fezes;

$\mathrm{t}=$ tempo de amostragem do indicador; $\mathrm{e}$

A e B = parâmetros biologicamente indefinidos.

O tempo médio de retenção (TMR) em cada compartimento foi expresso como o inverso da taxa de passagem:

$$
\mathrm{TMR}_{\text {rúmen }}=\frac{1}{\mathrm{k}_{1}} \text { e } \quad \mathrm{TMR}_{\text {pós-rúmen }}=\frac{1}{\mathrm{k}_{2}}
$$

A avaliação dos modelos foi realizada observando-se os desvios dos ajustamentos para cada modelo, os quais foram definidos como êi $=[\hat{\mathrm{Y}} \mathrm{i}(\mathrm{obs})-.\hat{\mathrm{Y}} \mathrm{i}(\mathrm{est})$. e padronizados conforme DRAPER e SMITH (1966). Para se escolher o melhor modelo, tomaram-se como base os valores dos desvios padronizados que fossem mais homogêneos, ou seja, os que mais se aproximassem de zero para cada tempo de coleta, e o número de corridas de sinal dos desvios, que deve ser o menor possível (DRAPER e SMITH, 1966; DHANOA et al., 1995; e VIEIRA et al. 1997).

Foram pesados aproximadamente $5 \mathrm{~g}$ de cama de frango ou de feno de coast-cross, que foram colocados em sacos de náilon $(7 \times 14 \mathrm{~cm})$ com poros de $50 \mu \mathrm{m}$, numerados externamente, mantendo-se a relação de $20 \mathrm{mg}$ de $\mathrm{MS} / \mathrm{cm}_{2}$ de área de superfície dos sacos, conforme recomendações de KIRKPATRICK e KENNELLY (1987).

Os sacos de náilon foram introduzidos no rúmen nos tempos de $0 ; 3 ; 6 ; 9 ; 12 ; 24 ; 36 ; 72$; e 96 horas, conforme recomendado por MERTENS (1993) para alimentos volumosos, e, posteriormente, todos foram retirados ao mesmo tempo. Imediatamente após serem removidos, foram colocados em balde com água fria para paralisação da atividade microbiana e, então, lavados em água corrente até que a mesma ficasse clara. Os sacos correspondentes ao tempo 0 $\mathrm{h}$ também foram lavados, juntamente com os anteriores. Terminada a lavagem, os mesmos foram secados em estufa de circulação forçada, com temperatura de $60 \pm 5^{\circ} \mathrm{C}$, por 48 horas, e então determinadas as porcentagens de MS, PB e FDN, no resíduo.

A porcentagem de desaparecimento da MS, PB e FDN em cada tempo de incubação foi calculada pela proporção de alimento que ficou nos sacos após a incubação no rúmen. Os parâmetros da cinética da degradação da MS, PB e FDN e a degradabilidade efetiva (DE) foram estimados utilizando-se os modelos descritos por ØRSKOV e McDONALD (1979) e McDONALD (1981).

\section{Resultados e Discussão}

O comportamento dos desvios padronizados nos tempos de coleta para os modelos Matis, GrovumWilliams e Dhanoa estão representados na Figura 1.

Os resultados sugerem que o modelo biexponencial Grovum-Williams, amplamente utilizado na literatura, se mostrou inapropriado para descrever a cinética de passagem das partículas pelo trato digestivo, o que pode ser atribuído à lenta ascensão na concentração de indicador nas fezes observada em quase todos os animais estudados (Figura 2), não obedecendo ao 
padrão teórico da curva de observações descrito por BLAXTER et al. (1956), cuja fase ascendente é bem menos inclinada.

ELLIS et al. (1979) obtiveram perfis parecidos com os descritos na Figura 2 e sugeriram que a inclusão da dependência do tempo em que a partícula já está no compartimento poderia resolver o problema. Isto fez com que se estudassem os dados desta pesquisa utilizando o modelo proposto por MATIS (1972), que incluiu ao modelo de BLAXTER et al. (1956) uma família gama tempo-dependente. O mode- lo Matis considera a alteração física que as partículas sofrem através dos processos digestivos no rúmen, já que a dependência do tempo é natural, pois a probabilidade de passagem através do esfíncter retículoomasal aumenta, à medida que a partícula diminui de tamanho. Esta diminuição, geralmente, se dá em função do tempo em que a partícula se encontra no rúmen. Entretanto, para este modelo, não houve bom ajuste dos dados, quando se observaram o perfil dos desvios padronizados e o número de corridas de sinal.

Os modelos Grovum-Williams e Matis apresen-

Matis

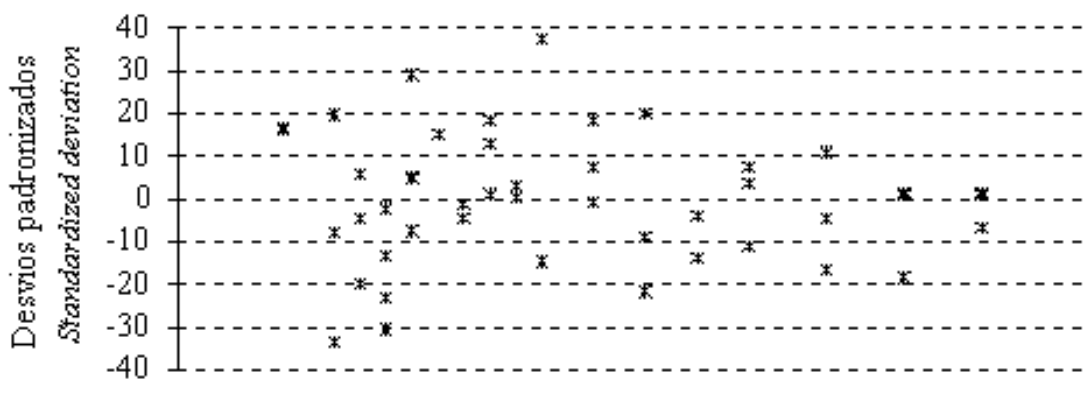

Grovum-Williams

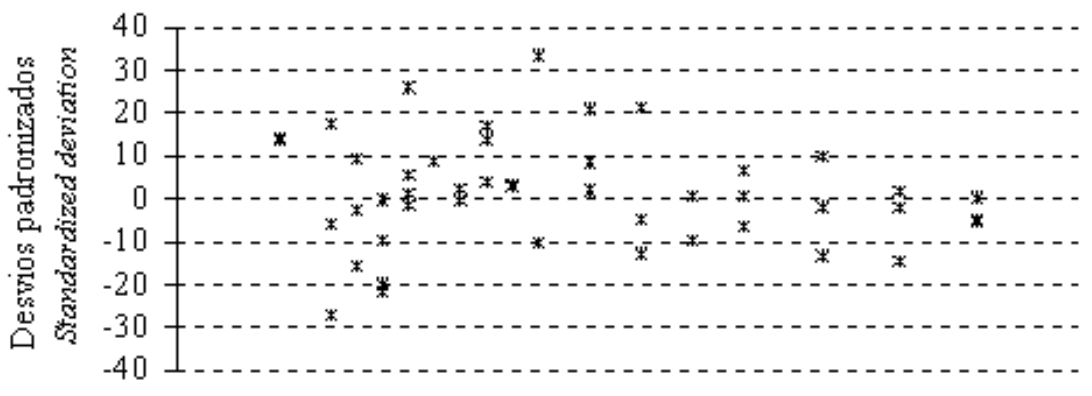

Dhanoa

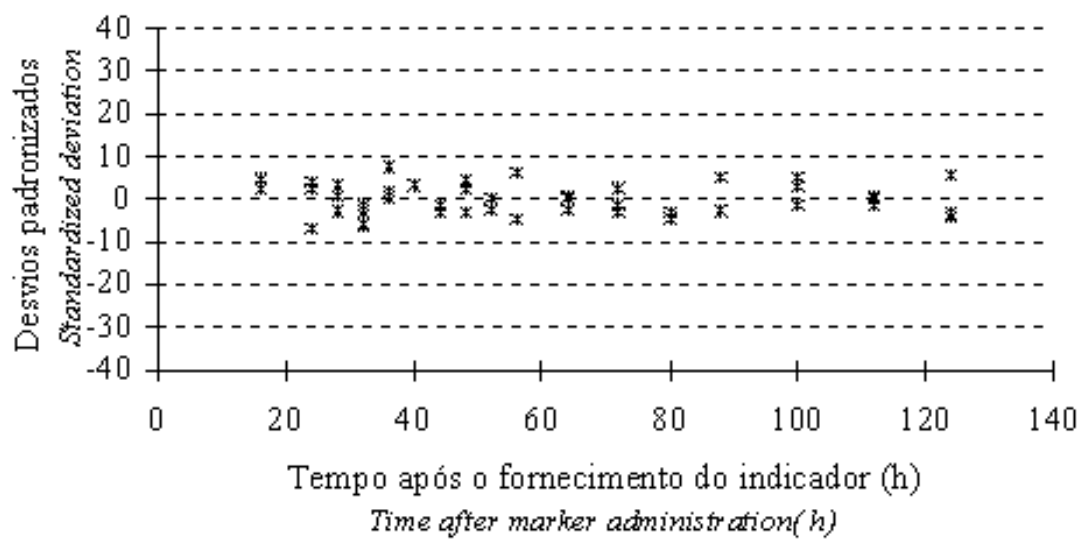

Figura 1 - Desvios padronizados para os diferentes modelos.

Figure 1 - Standardized deviation for the different models. 

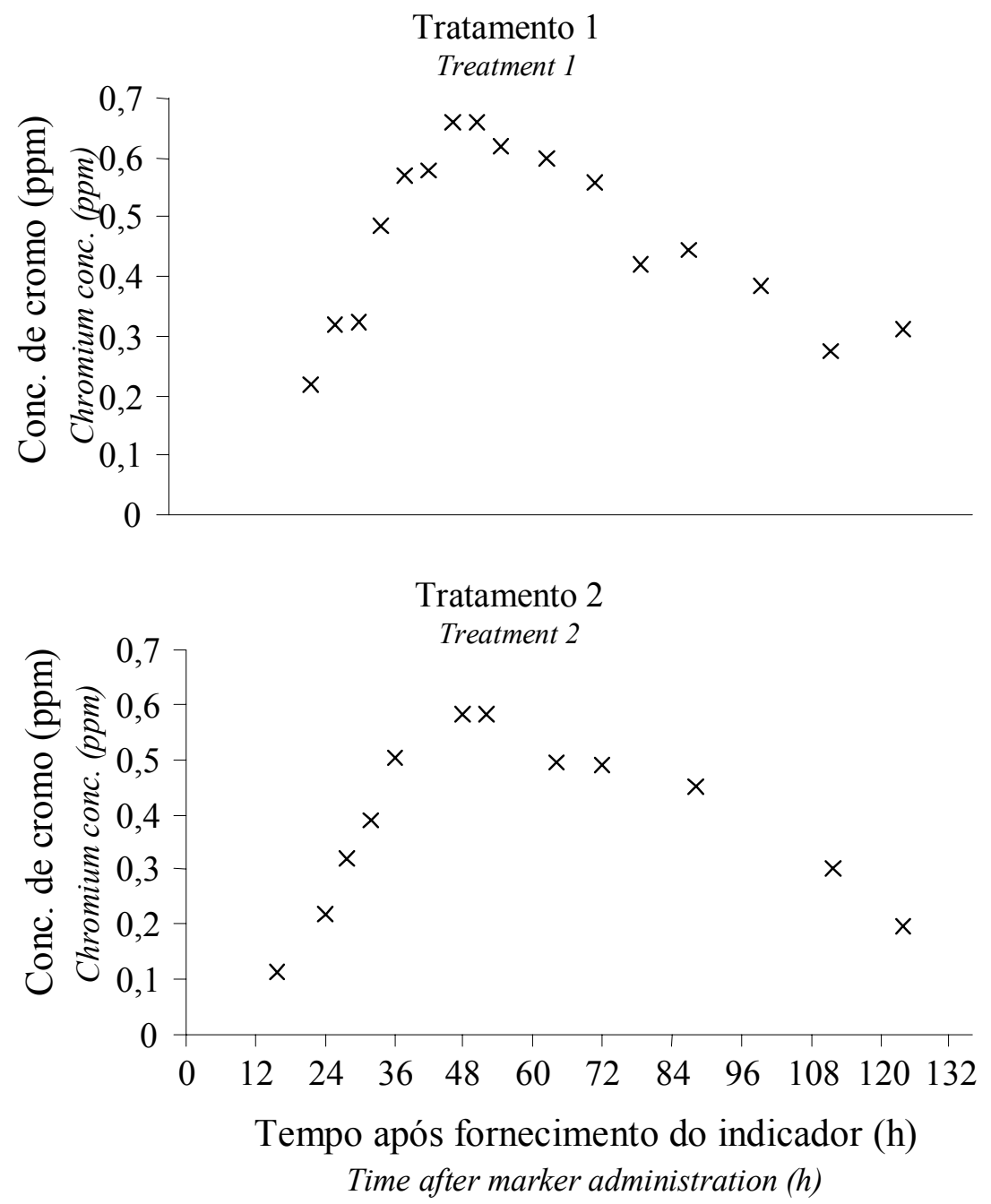

Figura 2 - Concentrações de indicador nas fezes de novilhos submetidos a dietas com dois níveis de suplemento à base de microbiota ruminal liofilizada (0 g/animalød - tratamento 1; $10 \mathrm{~g} / \mathrm{animal} \bullet d$ - tratamento 2), em função dos tempos de coleta (h).

Figure 2 - Marker concentration in the feces of steers fed diets with two supplement levels based on lyophilized ruminal microbiota (0 g/animal•d - treatment 1; $10 \mathrm{~g} / \mathrm{animal} \bullet d$ - treatment 2), in function of the sampling time $(\mathrm{h})$.

taram comportamento parecido quanto aos desvios padronizados. Pode-se observar que ambos superestimaram ou subestimaram algumas seções da distribuição residual, não apresentando boa aderência aos dados observados.

O melhor ajuste foi observado quando se utilizou o modelo Dhanoa, pois percebe-se claramente pela Figura 1 que este apresentou os desvios padronizados mais próximos de zero. Isto leva a crer que, nas condições deste experimento, a cinética de passagem apresentou comportamento tempo-dependente e o TGI dos novilhos pode ser representado por um número inespecífico de compartimentos exponenciais, com o padrão de excreção do marcador sendo definido, principalmente, por eventos que ocorrem dentro de dois compartimentos principais (rúmen $=>\mathrm{k}_{1}$ e intestinos $=>\mathrm{k}_{2}$ ).

A adequação deste modelo se confirma pelo número de corridas de sinal dos desvios padroniza- 
dos, o qual apresentou o menor valor para esta análise 21 corridas (DRAPPER e SMITH, 1966; DHANOA et al., 1995; e VIEIRA et al., 1997). Os modelos Grovum-Williams e Matis apresentaram 23 e 25 corridas de sinal, respectivamente.

Apesar dos estudos de comparação terem apontado o modelo Dhanoa como o mais adequado, as comparações do efeito de adição do suplemento à base de microbiota ruminal liofilizada à dieta dos novilhos também foram efetuadas para os outros dois modelos. Não se observou diferença significativa do suplemento sobre os valores de $\mathrm{k}_{1}$ e $\mathrm{k}_{2}$, o tempo médio de retenção das partículas no rúmen (TMRr) e nos intestinos (TMRi) e a relação TMRr/TMRi, conforme ilustrado na Tabela 3. Entretanto, as discussões serão efetuadas apenas tomando como base o modelo Dhanoa.

Como digestibilidade e taxa de passagem podem ser, ao mesmo tempo, efeito e causa do pool de nutrientes disponíveis aos animais, o fato de não ter havido diferença entre as taxas de passagem das partículas, com a adição do suplemento, nos dois compartimentos, provavelmente pode ser apontado como o responsável por não terem sido encontradas diferenças entre os coeficientes de digestibilidade da FDN, MS e MO (OLIVEIRA, 1998) ou vice-versa. Como a taxa de passagem é largamente influenciada pelo tamanho de partículas, que era o mesmo para todas as dietas, e pelo nível de consumo, que não apresentou diferença estatística entre os tratamentos (OLIVEIRA, 1998), os resultados relacionados às digestibilidades estão dentro do esperado, já que, segundo MERTENS e ELY (1982), os desvios indigestíveis são os principais fatores que influem no TMR dos alimentos no TGI.

A taxa de passagem das partículas no rúmen está acima do valor descrito pelo AGRICULTURAL RESEARCH COUNCIL - ARC (1984), que considera este valor sendo de $2 \% / \mathrm{h}$ e correspondente ao nível baixo de consumo de matéria seca.

Utilizando-se a equação empírica $\mathrm{r}=-0,024+0,179\left[1-\mathrm{e}^{(-0,278 \ell)}\right]$, do AGRICULTURAL AND FOOD RESEARCH COUNCIL - AFRC (1992), em que $r$ representa a taxa de passagem no rúmen e $\ell$, o nível de alimentação, pode-se inferir que, em função da taxa de passagem encontrada, o nível de alimentação dos animais nesta pesquisa se encontra entre 1,1 e 1,15 vezes a mantença.

BROSH et al. (1993), em ensaio com vacas de corte alimentadas com dietas que continham $15 \%$ de cama de frango, encontraram 31,8 horas para o
TMRr, enquanto nesta pesquisa o tempo foi de 42,37 horas. Já os valores para o TMRi, de 68,8 h, encontrados por esses autores apresentaram-se mais elevados que os descritos neste trabalho (14,62 h). Em função disso, esses autores constataram razão TMRr/ TMRi menor. Os valores elevados para o TMRi, descritos por BROSH et al. (1993), vão de encontro ao proposto por GROVUM e WILLIAMS (1973), que descrevem o turnover intestinal como mais rápido que no rúmen-retículo.

PATIL et al. (1993), em trabalho com novilhas holandesas alimentadas com feno de bermuda (Cynodon dactylon) suplementado com aproximadamente 8 e $15 \%$ de cama de frango, encontraram, para ambos os níveis de inclusão, $3,21 \% / \mathrm{h}$ de taxa de passagem das partículas. $O$ valor encontrado na presente pesquisa está abaixo do descrito por esses autores. Esta maior taxa de passagem provavelmente ocorreu porque esses pesquisadores utilizaram cama de frango cuja base era casca de arroz. Este material apresenta tamanho de partícula menor que o material base da cama de frango (capim-elefante em adiantado estádio de maturidade), o que proporciona maior taxa de escape para os intestinos.

Os dados referentes à fração prontamente solúvel (a); fração insolúvel potencialmente degradável (b); taxa de degradação da fração $b(c)$; e DE da MS, PB e FDN do feno de coast-cross e da cama de frango constam da Tabela 4.

Para a estimativa da DE, foi utilizado o valor de $\mathrm{k}_{1}=2,36$ e $2,31 \% / \mathrm{h}$, respectivamente, para o tratamento em que se administrou ou não o suplemento. Estes valores foram gerados pelo modelo Dhanoa.

A exemplo do ocorrido com a taxa de passagem, a adição do suplemento à base de microbiota ruminal não influenciou os parâmetros estimados $(\mathrm{P}<0,05)$.

Os coeficientes $b$ (fração insolúvel, mas potencialmente degradável) e $c$ (taxa de degradação da fração $b$ ), para MS do feno de coast-cross encontrados nesta pesquisa (52,87 e 2,39, respectivamente), foram similares aos de DEMITO (1993). Esse autor observou valores de $10,46 \%$ para a fração a (fração prontamente solúvel) e $39,24 \%$ para a $\mathrm{DE}$, que se encontram abaixo dos observados neste ensaio (17,30 e 45,16\%). Ao refazer os cálculos para DE, utilizando a taxa de passagem estimada neste ensaio $(2,66 \% / \mathrm{h})$, pode-se notar que a diferença aumenta mais ainda, todavia, deve-se levar em consideração que esse autor trabalhou com ovinos.

As degradabilidades efetivas da MS (45,5\%) e PB $(60,8 \%)$ do feno de coast-cross encontrados por 
AROEIRA et al. (1994) apresentaram-se próximas às constatadas nesta pesquisa. Salienta-se que esses autores trabalharam com taxa de passagem fixa de 5\%.

Para a PB do feno, a DE se apresentou próxima à descrita nos estudos de DEMITO (1993), 59,93\%. Entretanto, esse autor encontrou resultados bem diferentes para os parâmetros $a, b$ e $c$, que foram 16,06 ; 42,26 ; e $4,79 \%$, contra os 34,$58 ; 46,69$; e $2,68 \%$ encontrados nesta pesquisa, respectivamente. Essas diferenças podem ter ocorrido basicamente em função da variabilidade existente entre os volumosos utilizados, quanto à composição químico-bromatológica e ao estádio de crescimento no momento do corte. Este é um exemplo interessante de dois alimentos que apresentam praticamente a mesma $\mathrm{DE}$, entretanto, a eficiência de utilização da proteína pode variar substancialmente em animais recebendo a mesma dieta. Isto se dá examinando o perfil dos parâmetros $a, b$ e $c$, quando se observa que o feno utilizado neste trabalho possui uma fração prontamente solúvel no rúmen bem mais alta e, apesar de apresentar a fração $b$ similar ao utilizado por DEMITO (1993), a taxa de digestão (c) desta é mais lenta. Então, a dieta a ser balanceada com este feno deve oferecer fontes de carboidratos cuja taxa de fermentação ruminal seja relativamente rápida, de modo que forneça energia para que os microrganismos possam utilizar eficientemente a $\mathrm{PB}$.

Para a FDN do feno e da cama de frango, é possível que a degradabilidade efetiva esteja super estimada, já que os valores gerados pelo modelo para a fração $a$ não têm significado biológico, pois a FDN não possui fração solúvel e a porcentagem de desaparecimento observada no modelo foi zero.

O feno apresentou DE da FDN (39,75\%) com valores próximos aos encontrados por DEMITO (1993), 39,52\%. Todavia, os valores de $a$ e $b$ observados por esse autor apresentaram-se menores $(3,77$ e $51,46 \%)$ e o valor de $c$ foi maior (4,55\%).

Os resultados encontrados para as frações $a$ e $c$ da MS e PB da cama de frango apresentaram-se maiores que os descritos por VALADARES FILHO et al. (1990), já o coeficiente $b$ apresentou-se menor. Com isto, a degradabilidade efetiva destes dois nutrientes, descrita nesta pesquisa, apresentou-se maior que a encontrada por esses autores.

Os valores de $a$ para a PB da cama de frango demonstram que, aproximadamente, $71 \%$ da proteína deste estão prontamente disponíveis no rúmen. Este número, provavelmente, pode ser atribuído à presença, neste alimento, de alto teor de NNP, que, segundo ROFFLER e SATTER (1974), é um componente $100 \%$ degradável no rúmen. A cama de frango deve ser então utilizada juntamente com uma fonte energética de fermentação relativamente rápida no rúmen, para a máxima eficiência microbiana de utilização do N. Todavia, este fato é mais contundente quando se refere à utilização de outras fontes de NNP, como a uréia, pois o ácido úrico é solubilizado no rúmen de forma mais lenta (OLTJEN et al., 1968).

O teor de FDN da cama de frango apresenta perfil de degradação bem mais lento que o do feno.

Tabela 3 - Taxa de passagem no rúmen $\left(k_{1}\right)$ e nos intestinos $\left(k_{2}\right)$, tempo médio de retenção das partículas no rúmen $\left(T M R_{r}\right)$ e nos intestinos $\left(T M R_{i}\right)$ e relação $T M R_{r} / T M R_{i}$, para os modelos propostos

Table 3 - Rumen $\left(k_{1}\right)$ and intestinal $\left(k_{2}\right)$ rate of particulate passage, ruminal $\left(M R T_{r}\right)$ and intestinal $\left(M R T_{j}\right)$ mean of retention time and MRT, $M R T_{i}$ ratio, for the studied models

\begin{tabular}{|c|c|c|c|c|c|c|}
\hline \multirow[t]{2}{*}{ Item } & \multicolumn{2}{|c|}{ Matis } & \multicolumn{2}{|c|}{ Grovum-Williams } & \multicolumn{2}{|c|}{ Dhanoa } \\
\hline & $\mathrm{SS}^{1}$ & $\mathrm{CS}^{2}$ & SS & $\mathrm{CS}$ & SS & $\mathrm{CS}$ \\
\hline$\overline{\mathrm{k}_{1}(\% / \mathrm{h})}$ & 3,10 & 2,99 & 2,53 & 2,65 & 2,36 & 2,31 \\
\hline $\mathrm{k}_{2}(\% / \mathrm{h})$ & 7,66 & 7,88 & 4,40 & 4,67 & 6,84 & 7,07 \\
\hline $\mathrm{TMR}_{\mathrm{r}}(\mathrm{h})$ & 32,25 & 33,44 & 39,53 & 37,74 & 42,37 & 43,29 \\
\hline$M R T_{r}(h)$ & & & & & & \\
\hline $\mathrm{TMR}_{\mathrm{i}}(\mathrm{h})$ & 13,05 & 12,69 & 22,73 & 21,41 & 14,62 & 14,14 \\
\hline$M R T_{i}(h)$ & & & & & & \\
\hline $\begin{array}{l}\mathrm{TMR}_{\mathrm{r}} / \mathrm{TMR}_{\mathrm{i}} \\
M R T_{r} / M R T_{i}\end{array}$ & 2,47 & 2,63 & 1,74 & 1,76 & 2,90 & 3,06 \\
\hline
\end{tabular}

${ }^{1} \mathrm{SS}$ - Sem suplemento à base de microbiota ruminal liofilizada. SS - Without supplement based on lyophilized ruminal microbiota.

2 CS - Com suplemento à base de microbiota ruminal liofilizada. SS - With supplement based on lyophilized ruminal microbiota 
Tabela 4 - Parâmetros da cinética de degradação ruminal da matéria seca (MS), proteína bruta (PB) e fibra em detergente neutro (FDN) do feno de coast-cross e da cama de frango

Table 4 - Kinetics parameter of ruminal degradation for dry matter (DM), crude protein (CP) and neutral detergent fiber (NDF) of coast-cross hay and of broiler litter

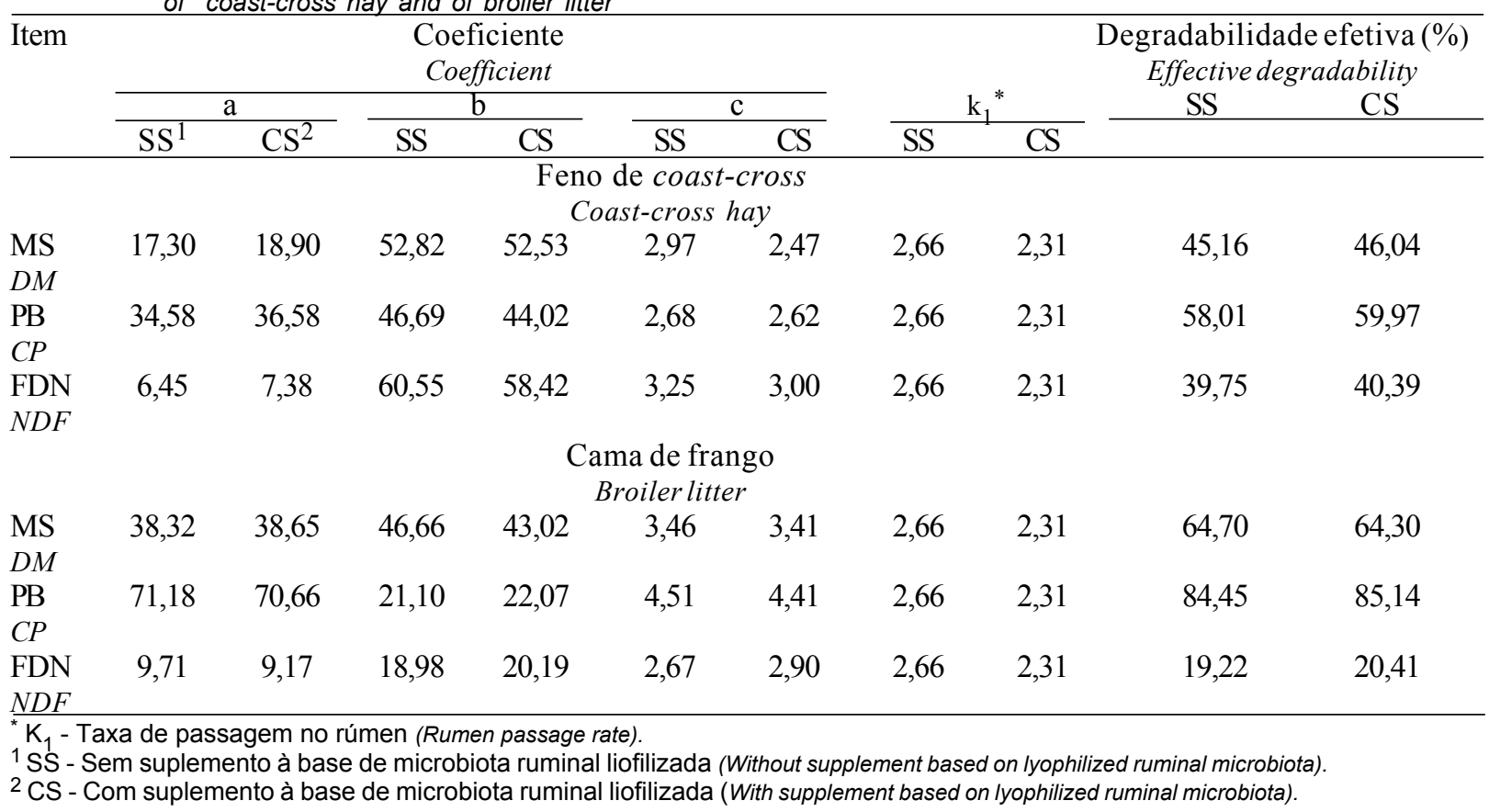

Isto ocorre, provavelmente, pelo fato de a cama de frango ter como base o capim-elefante em estádio avançado de maturidade, que é altamente lignificado.

\section{Conclusões}

A utilização diária de $10 \mathrm{~g}$ do suplemento, por animal, não influiu na taxa de passagem das partículas e na degradabilidaderuminal.

A cinética de passagem apresentou comportamento tempo-dependente.

O modelo Dhanoa mostrou-se mais eficiente na determinação dos parâmetros relativos à taxa de passagem.

\section{Referências Bibliográficas}

AGRICULTURAL AND FOOD RESEARCH COUNCIL - AFRC. 1992. Nutritive Requirements of ruminant animals: protein. Nutr. Abs. Rev., 62:787-835.

AGRICULTURAL RESEARCH COUNCIL - ARC. 1984. The nutrient requirements of ruminants livestock. Suppl. 1. Commonwealth Agricultural Bureau, Farnham Royal, U. K.

AITCHISON, E., GILL, M., FRANCE, J. et al. 1986. Comparison of methods to describe the kinetics of digestion and passage of fibre in sheep. J. Sci. Food Agric., 37:1065-1072.

AROEIRA,L.J.M.,LOPES, F.C.F.,DAYRELL, M.S. Degradabilidade de alimentos no rúmen de vacas holandes-zebu. In: REUNIÃO ANUAL DA SOCIEDADE BRASILEIRA DE ZOOTECNIA,
31, Maringá, 1994. Anais... Maringá: SBZ, p.530. 1994.

BLAXTER, K.L., GRAHAM, N.M., WAINMAN, F.W. 1956. Some observations on the digestibility of food by sheep, and on related problems. Br. J. Nutr., 10:69-91.

BOER, G., MURPHY, J.J., KENNELY, J.J. 1987. A modified method for determination of in situ rumen degradation of feedstuffs. Can. J. Anim. Sci., 67:93-102.

BROSH, A., HOLZER, Z., AHARONI, Y. et al. 1993. Intake, rumen volume, retention time and digestibility of diets based on poultry litter and wheat straw in beef cows before and after calving. J. Agric. Sci., 121:103-109.

DEMITO, A. Degradabilidade "in situ" de gramíneas e leguminosas com diferentes níveis de lipídeos na ração de ovinos. Maringá-PR: UEM, 1193, 69p. Monografia (Trabalho de Graduação) Universidade Estadual de Maringá, 1993.

DHANOA, M.S., FRANCE, J., SIDDONS, R.C. et al. 1995. Nonlinear compartmental model to describe forage degradation kinetics during incubation in polyester bags in the rumen. Br. J. Nutr., 51: 173-179.

DHANOA, M.S., SIDDONS, R.C., FRANCE, J. et al. 1985. A multicompartmental model to describemarker excretion in ruminant faeces. Br. J. Nutr., 53: 663-671.

DRAPER, N.R., SMITH, H. 1966. Applied regression analysis. New York, John Wiley \& Sons, Inc., 407 p.

ELLIS, W.C., MATIS, J.H., LASCANO, C. 1979. Quantitating ruminal turnover. Federation Proc., 38:2702-2706.

FAICHNEY, G.J. 1993. Digesta flow. In: FORBES, J.M., FRANCE, J. (eds) Quantitative of ruminant digestion and metabolism. Commonwealth AgriculturalBureaux, CambridgeUniversity Press, England, p.53-85.

FONTENOT, J.P., WEBB, K.E. 1975. Health aspects of recycling animal wastes by feeding. J. Anim. Sci., 40:1267-1277. 
FRANCE, J., THORNLEY, J.H.M., DHANOA, M.S. 1985. et al. On themathematics ofdigesta flow kinetics.J. Theor. Biol., 113:743-758.

GROVUM, W.L., WILLIAMS, V.J. 1973. Rate of passage of digesta in sheep. 4. Passage of marker through the alimentary tract and the biological relevance of rate-constants derived from the changes in concentration of marker in faeces. Br. J. Nutr., 30:313-329.

KIRKPATRICK, B.K., KENNELLY, J.J. 1987. In situ degradability of protein and dry matter from single protein sources and from a total diet. J. Anim. Sci., 65:567-576.

LEÃO, M.I., COELHO DA SILVA, J.F. Técnica de fistulação de abomaso em bezerros. In: REUNIÃO ANUAL DA SOCIEDADE BRASILEIRA DEZOOTECNIA, 17, Fortaleza, CE, 1980.Anais... Fortaleza: SBZ, 1980. p.37.

LEÃO, M.I., COELHO DA SILVA, J.F., CARNEIRO, L.N.D.M. 1978. Implantação de fístula ruminal e cânula duodenal reentrante em carneiros para estudos de digestão. $R$. Ceres, 25:4254.

MATIS, J.H. 1972. Gamma time-dependency in Blaxter's compartmental model. Biometrics, 28:597-602.

McCASKEY, T.A., ANTHONY, W.B. 1979. Human and animal health aspects of feeding livestock excreta. J. Anim. Sci., 48:163-171.

McDONALD, I. 1981. A revised model for the estimation of protein degradability in the rumen. J. Agric. Sci., 96:251-252.

MEHREZ, A.Z., ØRSKOV, E.R. 1977. A study of the artificial fibre bag technique for determining the digestibility of feeds in the rumen. J. Agric. Sci., 88:645-650.

MERTENS, D.R. 1993. Rate And extent of digestion. In: FORBES, J.M., FRANCE, J. (Eds) Quantitative of ruminant digestion and metabolism. Cambridge: Commonwealth Agricultural Bureaux, p.13-51.

MERTENS, D.R., ELY, L.O. 1982. Relationship of rate and extent of digestion to forage utilization- a dynamic model evaluation.J.Anim. Sci.,54: 895-905.

NATIONAL RESEARCH COUNCIL - NRC. 1989. Nutrient requirements of dairy cattle. $6 . \mathrm{ed} .157 \mathrm{p}$.

NOCEK, J.E. 1988. In situ and other methods to estimate ruminal protein and energy digestibility: a review. J. Dairy Sci., 71:2051-2069.

OLIVEIRA, R.L. Cinética digestiva em novilhos submetidos a dietas com diferentes níveis de cama de frango e de suplemento à base de microbiota ruminal. Viçosa, MG: UFV, 1998, 69p. Dissertação (Mestrado em Zootecnia) - Universidade Federal de Viçosa, 1998.

OLTJEN, R.R., SLYTER, L.L., KOZAK, A.S. et al. 1968. Evaluation of urea, biuret, urea phosphate and uric acid as NPN sources for cattle. J. Nutr., 94:193-202.

ØRSKOV, E. R., McDONALD, I. 1979. The estimation of protein degradability in the rumen from incubation measurements weighed according to rate of passage. J. Agric. Sci., 92:499-503.

PATIL, A.R., GOETSHC, A.L., GALLOWAY, D.L et al. 1993. Intake and digestion by Holstein steers calves consuming grass hay supplemented with broilerlitter. Anim. FeedSci. Technol.,44:251-263.

PETIT, H.V., SANTOS, G.T., PRADO, I.N. 1994. Alguns aspectos do novo sistema de arraçoamento protéico da vaca leiteira. $R$. Unimar, 16:89-110 (Supl. 1).

QUIROZ, R.A., POND, K.R., TOLLEY, E.A. et al. 1988. Selection among nonlinear models for rate of passage studies in ruminants. $J$. Anim. Sci., 66:2977-2986.

ROFFLER, R.E., SATTER, L.D. 1974. Relationship between ruminal ammonia and nonprotein nitrogen utilization by ruminants. I. Development ofamodel forpredicting nonproteinnitrogenutilization by cattle. J. Dairy Sci., 58:1880-1888.

ROMERO, F. 1990. Utilizacion de la tecnica de digestion in situ para la caracterización de forrajes. In: RUIZ, M.E., RUIZ, A. Nutrición de rumiantes: guia metodológica de investigación. Costa Rica: IICA. p.105-114.

RUSSELL, J.B., O'CONNOR, J.D., FOX, D.G. et al. 1992. A net carbohydrate and protein system for evaluating cattle diets. I. Ruminal fermentation. J. Anim. Sci., 70:3551-3561.

SNIFFEN, C. J., ROBINSON, P. H. 1987. Microbial growth and flow as influenced by dietary manipulation. J. Dairy Sci., 70:425-441.

UDÉN, P., COLUCCI, P. E., VAN SOEST, P. J. 1980. Investigation of chromium, cerium and cobalt as markers in digesta rate of passage studies. J. Sci. Food Agric., 31:625-632.

UNIVERSIDADEFEDERALDE VIÇOSA(UFV). SAEG(Sistemade Análises Estatísticas e Genéticas). Viçosa, MG, 1995.(Versão 7.0).

VALADARES FILHO, S.C., COELHODA SILVA, J.F., LEÃO, M.I. et al. 1990. Degradabilidade in situ da matéria seca e proteína bruta de vários alimentos em vacas em lactação. R. Soc. Bras. Zootec., 20:111-122

VAN SOEST, P.J. 1994. Nutritional ecology of the ruminant. 2. ed. Cornell University Press, Ithaca, 476p.

VIEIRA, R.A.M., PEREIRA, J.C., MALAFAIA, P.A.M. et al. 1997. Application of non-linear models in the description of in situ degradation profiles of the elephant grass (Pennisetum purpureum Schum., Mineiro variety). Anim. Feed Sci. Technol., 66:197-210.

Recebido em: $28 / 05 / 98$

Aceito em: 25/01/99 